\title{
LETTER
}

\section{Spread of North American wind-dispersed trees in future environments}

Ran Nathan, ${ }^{1 *}$ Nir Horvitz, ${ }^{1}$ Yanping He, ${ }^{2}$ Anna Kuparinen, ${ }^{3}$ Frank M. Schurr ${ }^{4}$ and Gabriel G. Katul ${ }^{5}$

\begin{abstract}
Despite ample research, understanding plant spread and predicting their ability to track projected climate changes remain a formidable challenge to be confronted. We modelled the spread of North American winddispersed trees in current and future (c. 2060) conditions, accounting for variation in 10 key dispersal, demographic and environmental factors affecting population spread. Predicted spread rates vary substantially among 12 study species, primarily due to inter-specific variation in maturation age, fecundity and seed terminal velocity. Future spread is predicted to be faster if atmospheric $\mathrm{CO}_{2}$ enrichment would increase fecundity and advance maturation, irrespective of the projected changes in mean surface windspeed. Yet, for only a few species, predicted wind-driven spread will match future climate changes, conditioned on seed abscission occurring only in strong winds and environmental conditions favouring high survival of the farthest-dispersed seeds. Because such conditions are unlikely, North American wind-dispersed trees are expected to lag behind the projected climate range shift.
\end{abstract}

\section{Keywords}

Climate change, demography, dispersal, fat-tailed dispersal kernels, forecasting, forests, invasion by extremes, long-distance dispersal, mechanistic models, plant migration, population spread, range expansion, survival, wind dispersal.

Ecology Letters (2011) 14: 211-219

\section{INTRODUCTION}

The ability of plants to spread into new areas shapes the large-scale structure and dynamics of plant populations and communities (Levin et al. 2003; Svenning \& Skov 2007). Human-induced changes to climate, land use, disturbance regimes, habitat fragmentation and biological invasions have made the evaluation of the spread capacity of plants ever more urgent (Foley et al. 2005). In particular, nearsurface temperature shifts are expected to be rapid, propagating at $c$. 300-500 $\mathrm{m} \mathrm{year}^{-1}$ in northern hemispheric biomes (Loarie et al. 2009). These rapid shifts - considered to reflect shifts in species' habitats - cast doubts on the ability of plant species to track climate change (Malcolm et al. 2002; Higgins et al. 2003; McKenney et al. 2007; Svenning \& Skov 2007). Consequently, estimating the spread capacity is critical for assessing the future distributions and the risks of local and global extinction of plant species (Thuiller et al. 2005; Morin \& Thuiller 2009).

Assessments of spread capacity in future environments were chiefly derived from correlative niche-based models, and, to a lesser extent, from process-based species distribution models (Morin \& Thuiller 2009). The niche-based approach does not incorporate underlying mechanisms, and both approaches typically assume either unlimited or zero dispersal; yet, dispersal capacity of real species lie between these extremes and only few species, if any, match this assumption.
Strikingly different predictions of species distribution under climate change scenarios were obtained by models incorporating more realistic dispersal kernels compared with models assuming that dispersal is unlimited or null (Engler \& Guisan 2009).

Most studies implementing realistic descriptions of dispersal estimated the dispersal kernel from local measurements and then extrapolated broadly beyond the scale of measurements, in both time and space (e.g. Clark et al. 2001). Demography was typically simplified in these models to two composite parameters, the net reproductive rate $\left(R_{0}\right)$ and the generation time $(T)$. Further refinements of demography in spread models have incorporated more complex matrix population models (Neubert \& Caswell 2000; Buckley et al. 2005), but combined them with phenomenological dispersal kernels.

Spread models that incorporate both dispersal and demography mechanistically are promising tools for assessing the spread capacity of plants in future environments (Jeltsch et al. 2008; Thuiller et al. 2008). Their major drawbacks are relative complexity and the uncertainty as to whether their predictions are necessarily more accurate than those of simpler phenomenological spread models. Their major advantage is their ability to incorporate the effects of key determinants of population spread and, consequently, to forecast how environmental changes will affect potential spread. Only two recent studies of plant spread have implemented both dispersal and demography in a detailed mechanistic manner (Jongejans et al. 2008;

\footnotetext{
${ }^{1}$ Movement Ecology Laboratory, Department of Ecology, Evolution and Behavior, The Alexander Silberman Institute of Life Sciences, The Hebrew University of Jerusalem, Edmond J. Safra Campus, Jerusalem 91904, Israel ${ }^{2}$ School of Earth and Ocean Science, University of Victoria, Victoria, 
Soons \& Bullock 2008). Their importance notwithstanding, these studies have applied the full mechanistic approach to only one or two species, assumed that dispersal and demographic parameters are invariant in space and time, and did not examine spread in the context of future environmental changes. In a third comparable study, we have recently implemented a mechanistic wind-dispersal model to assess spread in warmer future environments (Kuparinen et al. 2009). Yet, this study focused on only two hypothetical species and a particular atmospheric process occurring under rather specific conditions (see supplementary material in Kuparinen et al. 2009), using empirical micrometeorological data from only one weather station, simplifying demography to only two parameters $\left(\mathrm{R}_{0}\right.$ and $\left.\mathrm{T}\right)$ that were assumed to be constant in time and space. Thus, the two major merits of the promising fully mechanistic approach - of (a) evaluating how projected environmental changes would affect spread rates of multiple plant species in spatially and temporally variable future landscapes, and (b) assessing the relative importance of key demographic, dispersal and environmental factors impacting spread process - have not yet been realized.

We address the general challenge of assessing the spread capacity of plants in future environments by means of a detailed mechanistic modelling approach that incorporates projected environmental and biological changes and enables quantitative evaluation of the role of key demographic and dispersal factors in determining spread rate. Focusing on North American wind-dispersed tree species, a large (>200 spp.) ecologically and economically important functional group of woody plants, we combined global sensitivity analysis with spread calculations for a typical hypothetical species as well as 12 specific 'real' species (see Methods section), to address four main objectives of assessing: (a) realistic lower and upper bounds of spread capacity of North American wind-dispersed tree species in future $(c$. 2060) environments, given projected changes in fecundity, maturation time and mean surface windspeed; (b) the relative role of $10 \mathrm{key}$ demographic and dispersal factors in determining the potential spread rate of wind-dispersed trees in general and their response to projected environmental changes in particular; (c) the uncertainty in predicting spread given uncertainty about two poorly quantified and largely unexplored potential determinants of plant spread: windspeeddependent seed abscission and post-dispersal seed-to-adult survival; and (d) the role of spatial variation in post-dispersal survival in determining future spread of trees.

\section{METHODS}

\section{Modelling spatial spread of wind-dispersed plant populations}

To assess the potential spread of wind-dispersed trees in future environments, we introduce three major modifications to the 'invasion-by-extremes' (IBE) modelling approach (Clark et al. 2001). The IBE approach assumes that the spread rate of a population is exclusively determined by extreme jumps of the farthest-forward individuals ahead of the continuous population. After multiple generations, the spread rate will be determined by the dispersal of the farthest individuals, even though initially dispersal from multiple seed sources in a large continuous population may cause faster spread rates (Clark et al. 2001). We extend and adjust the basic IBE approach to develop a general mechanistic model for the spread of winddispersed plants; the general scheme is illustrated in Fig. 1 and the mathematical details are provided in Appendix S1.
Although the IBE approach was first applied by implementing phenomenological (empirically fitted) dispersal kernels (Clark et al. 2001), a recent application has demonstrated the utility of incorporating mechanistic dispersal models to predict species response to environmental changes (Kuparinen et al. 2009). The analytical winddispersal model WALD (Katul et al. 2005) is particularly suitable for such applications because, unlike analytical phenomenological models, its parameters correspond to measurable factors determining wind dispersal: mean horizontal windspeed $(\overline{\mathrm{U}})$, standard deviation of vertical wind velocity $\left(\sigma_{\mathrm{w}}\right)$, seed terminal falling velocity $\left(\mathrm{v}_{\mathrm{t}}\right)$ and the height of seed release $\left(h_{r}\right)$. It is convenient to express $h_{r}=h_{t} \times p_{r}$, where $h_{t}$ is the tree height and $p_{r}$ is the proportional height of seed release. WALD leads to an inverse Gaussian fat-tailed distribution that accommodates parameter combinations representing coherent turbulent updrafts inducing seed uplift, the principle mechanism responsible for long-distance dispersal (LDD) of seeds by wind (Nathan et al. 2002) but ignores numerous other processes such as canopy interception. Thompson \& Katul (2008) modified WALD to incorporate a Weibull-distributed $\overline{\mathrm{U}}$ characterizing the spatiotemporal variation in wind conditions experienced by dispersed seeds. Thus, our first modification of the IBE approach - following essentially the same approach of Thompson \& Katul (2008) - is to mechanistically implement dispersal by integrating WALD kernels with Weibulldistributed $\bar{U}$ (Appendix S1), enabling detailed representation of the variation in atmospheric conditions at relevant spatiotemporal scales including projected windspeeds in different future scenarios.

The incorporation of multiple Weibull-based WALD kernels also enables incorporating biased (windspeed-dependent) seed abscission. It has long been argued that seed release of many wind-dispersed species is sensitive to temperature, relative humidity and windspeed. Preferential seed abscission in strong winds has been demonstrated empirically for temperate (Greene \& Johnson 1992) and tropical trees (Wright et al. 2008). Soons \& Bullock (2008) showed that spread models incorporating non-random seed abscission yield twofold faster spread compared with models assuming random seed abscission. Here, we assume that seeds abscise only above a threshold windspeed $\left(\overline{\mathrm{U}}_{\mathrm{r}}\right)$. As $\overline{\mathrm{U}}_{\mathrm{r}}$ is unknown for all tree species, we examined its importance in the uncertainty analyses described below.

Clark et al. (2001) decomposed $\mathrm{R}_{0}$ to its two basic components: (pre-dispersal) fecundity $(\beta)$ and (post-dispersal) seed-to-adult survival $(\phi)$. Trees typically have high $\beta$ and low $\phi$ (Bonner \& Karrfalt 2008; for typical values of these two parameters, see section IV in Appendix S1 and Table S2). Partitioning pre- and post-dispersal processes enables relaxing the critical assumption of spatially homogeneous survival of all previous IBE applications, which is critical for assessing the spread in changing environments. Thus, our second modification of the IBE approach is to incorporate spatially variable survival, $\phi(x)$, assuming a hump-shaped pattern of survival vs. distance (Nathan 2006). The increase in $\phi(\mathrm{x})$ at relatively short distances corresponds to the so-called Janzen-Connell (JC) effects, in which offspring mortality due to pathogens, seed predators and/or herbivores declines with increasing distance from the seed source (Janzen 1970). Although other survival patterns have also been observed (Nathan \& Casagrandi 2004), the JC pattern is fairly common and has clear biological interpretation (Janzen 1970). As survival data are collected only at relatively small scales, the shape of $\phi(\mathrm{x})$ at large scales in general, and the spatial scale of JC effects in particular, are largely unknown. Nevertheless, beyond a certain distance, JC effects are likely to be overridden by the opposing effects of spatial autocorrelation in abiotic 
Figure 1 Schematic representation of a general spread model of wind-dispersed tree species, modified from the invasion by extremes' modelling approach (Clark et al. 2001). The scheme illustrates the temporal (progressing downward along the vertical axis) and spatial (progressing to the right along the horizontal axis) dimensions of the process of spatial spread. The model incorporates five dispersal and five demographic parameters specified in the boxes. The key assumptions assert that population spread occurs solely via seeds dispersed isotropically from the farthest reproductive individual (thick arrows), and that each farthest individual disperses seeds during its entire reproductive period, starting when it becomes reproductive (i.e. reaching maturation age) and terminating when it dies (i.e. reaching longevity). The number of seeds dispersed during this period depends on the annual fecundity in years of good seed crops and the intercrop interval. The mean height of seed release is the product of tree height and the proportional height of seed release. Factors affecting seed flight trajectory (thin lines), hence dispersal distance, include seed terminal velocity, mean horizontal windspeed and the standard deviation of the vertical wind velocity. The distribution of dispersal distances and the probability of dispersed seeds to survive to maturity jointly determine the location of the farthest reproductive individual of the next generation.

conditions: farther away from the parent tree, environmental conditions will tend to be less similar (Tobler's first law of geography; Nekola \& White 1999), hence less suitable. A logical portray of survival is thus an asymmetric hump-shaped function such as the twoparameter log-logistic function (Appendix S1). For simplicity, we fixed the two parameters of this function and varied a third multiplying parameter so that the variation in survival is represented by a single parameter reflecting spatially averaged survival $(\Phi)$. We vary $\Phi$ over four orders of magnitude and compare spatially variable survival with both spatially uniform survival assumed in previous studies and spatially stochastic survival (Appendix S1).

Clark et al. (2001) also decomposed the generation time (T) to its basic components, maturation age $\left(t_{M}\right)$ and longevity $\left(t_{L}\right)$, and yet assumed that all seeds produced during the reproductive lifetime $\left(t_{L}-t_{M}\right)$ are dispersed 'at once' (Appendix S1). They also assumed that each tree disperses $\beta$ seeds every year, whereas the majority of winddispersed tree species in temperate and boreal forests exhibit iteroparous reproduction, typically producing large seed crops in an average intercrop interval ( $t_{\text {IC }}$ ) of 1-8 years (Bonner \& Karrfalt 2008). All else being equal, spread is faster if the farthest LDD occurs at $t_{M}$ rather than $t_{\mathrm{L}}$, and if $\mathrm{t}_{\mathrm{IC}}$ is shorter. Therefore, our third modification of the IBE approach is to explicitly incorporate iteroparous reproduction. By incorporating inter-specific variation in the basic components of tree reproduction $\left(\beta, t_{M}, t_{L}\right.$ and $\left.t_{I C}\right)$, we obtain a more realistic representation of the variance in fecundity schedule and lifetime reproduction.

\section{Effects of environmental changes on wind-driven spread}

Forecasts of long-term climate and non-climate environmental changes are inevitably uncertain (Allen et al. 2000; Murphy et al.

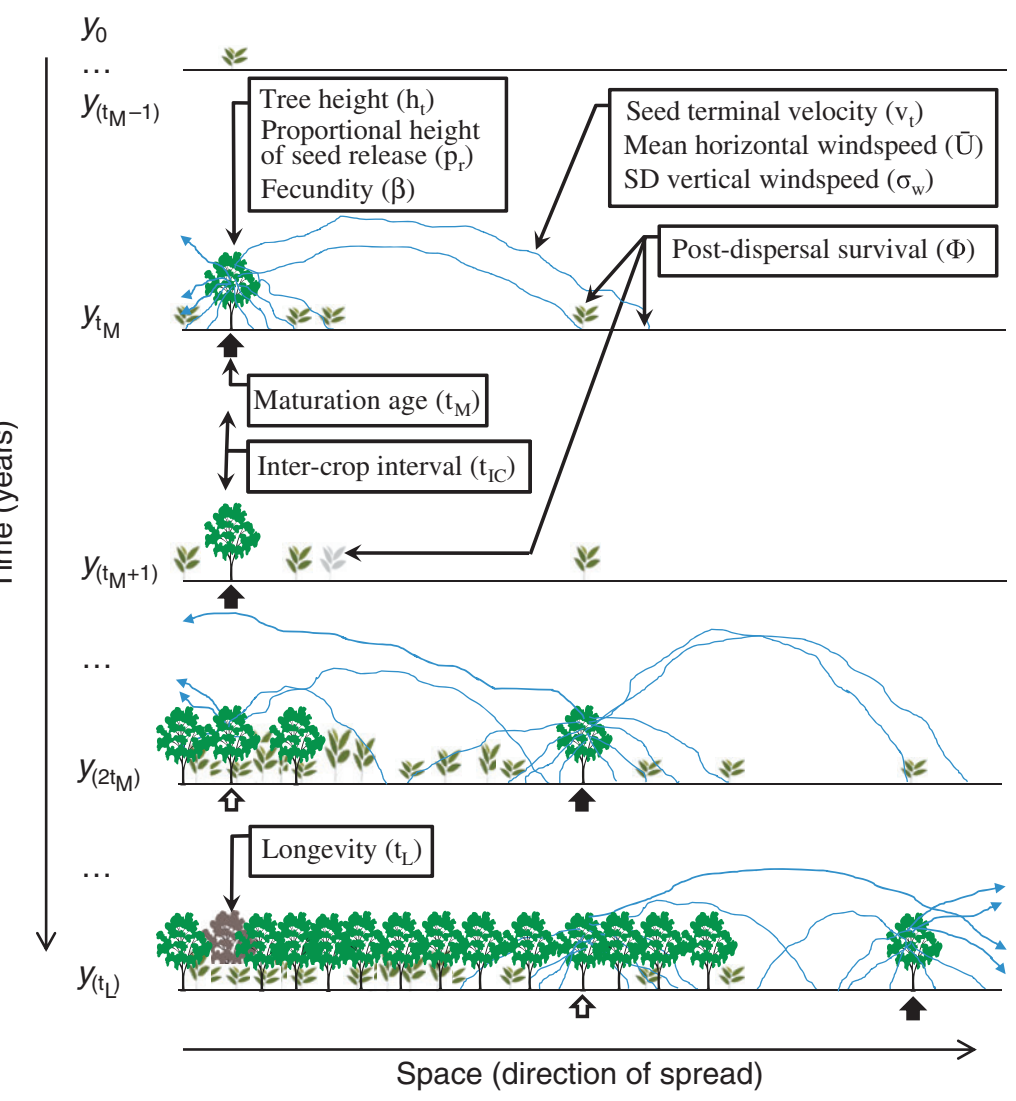

2004). Furthermore, given the complexity of the processes regulating plant spread and the lack of data on two key factors - the large-scale pattern of seed-to-adult survival and windspeed-dependent seed abscission - it is difficult to accurately estimate the spread rate for a particular species at a given geographic location under specific climatic scenarios. To frame logical bounds on how plant spread can be altered by future environmental changes, we applied a broad range of biologically sensible $\Phi$ and $\overline{\mathrm{U}}_{\mathrm{r}}$ values, and assessed the impact of uncertainty embedded in projected changes in windspeed, fecundity and maturation time.

Wind-dispersed trees are common in temperate and boreal forests (Bonner \& Karrfalt 2008), where the most pronounced climate changes are projected to occur (Malcolm et al. 2002). Estimates of horizontal velocity change in mean near-surface temperature that incorporate topographic effects suggest that, during the 21 st century, forests in high latitudes would face slower change than previously estimated due to the complex terrain characterizing forested biomes in high latitudes (Loarie et al. 2009). These relatively low estimates still project rather high rate of climatic range shift with mean values of $110 \mathrm{~m}_{\text {year }}{ }^{-1}$ for temperate conifer forests, $350 \mathrm{~m} \mathrm{year}^{-1}$ for temperate broadleaf and mixed forests, and $430 \mathrm{~m} \mathrm{year}^{-1}$ for boreal forests (Loarie et al. 2009).

To assess the current distribution of $\overline{\mathrm{U}}$, we fitted the commonly assumed Weibull distribution (Appendix S1) to 21-year (1979-1999) three-hourly surface wind records from 776 weather stations across North America (He et al. 2010). To assess the windspeed distribution expected for the middle of this century (2049-2069), we combined two complementary methods. The first approach, a linear extrapolation from measurements of surface windspeed during the last five decades (1953-2006) to the middle of the current century, yields 
changes of $-7 \%$ to $3 \%$ in windspeed over Canada (Wan et al. 2010). A comprehensive analysis of eight datasets, including observations, reanalysis and wind predictions from regional climate models, revealed a declining mean surface windspeed of similar magnitude over most regions of the USA (Pryor et al. 2009). The second approach uses the Canadian Regional Climate Model version 4, driven by the third-generation Canadian Global Circulation Model under the A2 emission scenario (Nakišenoviš et al. 2000), to predict lower and upper bounds of windspeeds for our forecast horizon (2049-2069) over North America. Altogether, these simulations predict both negative and positive changes in surface windspeed, with Weibull scale parameter within $[-4 \%,+6 \%]$ (overall mean change $1 \%$ ) and the shape parameter within $[-6 \%,+6 \%]$ (overall mean change $0.7 \%$ ). Combining the two methods, the lower and upper bounds for the proportional change in mean surface windspeed are $-7 \%$ and $+6 \%$ respectively (for more details, see Appendix S1).

The spatial spread of trees can also be altered by effects of increased atmospheric $\left[\mathrm{CO}_{2}\right]$ on reproduction. In the free-air $\mathrm{CO}_{2}$ enrichment (FACE) experiment at Duke Forest, Eastern USA, loblolly pine (Pinus taeda) trees in elevated $\left[\mathrm{CO}_{2}\right](+200 \mathrm{ppm})$ plots produced nearly twice as many seeds after 8 years, and reached maturity significantly earlier $\left(7 \%\right.$ reduction in $\left.\mathrm{t}_{\mathrm{M}}\right)$, compared with nearby trees in ambient $\left[\mathrm{CO}_{2}\right]$ (LaDeau \& Clark 2006). For emission scenario A2 (see above), this elevated $\left[\mathrm{CO}_{2}\right]$ of $c .570 \mathrm{ppm}$ is expected for our forecast horizon (the middle of the current century). Higher $\left[\mathrm{CO}_{2}\right](704 \mathrm{ppm})$ caused up to sevenfold increase in acorn production in a Florida scrub-oak forest (Stiling et al. 2004). A lower yet significant increase in seed production $(16 \%)$ was found in a meta-analysis of 79 domesticated and wild crop species grown under elevated $\left[\mathrm{CO}_{2}\right](500-800 \mathrm{ppm})$ (Jablonski et al. 2002).

\section{Model runs and statistical analyses}

Altogether, the modified-IBE spread model includes five demographic $\left(\beta, t_{\mathrm{M}}, \mathrm{t}_{\mathrm{L}}, \mathrm{t}_{\mathrm{IC}}\right.$ and $\left.\Phi\right)$ and five dispersal $\left(\overline{\mathrm{U}}, \sigma_{\mathrm{w}}, \mathrm{v}_{\mathrm{t}}, \mathrm{h}_{\mathrm{t}}\right.$ and $\left.\mathrm{p}_{\mathrm{r}}\right)$ parameters. To address the study objectives outlined in the Introduction section, we conducted three types of analyses of this basic model. In the first analysis, we assessed the relative importance of the 10 basic parameters in determining spread rate. Towards this end, we varied these parameters according to their distribution across the observed natural range (Fig. S6), based on a comprehensive literature survey (Table S2), and ran Monte-Carlo sensitivity analysis to examine their relative impact on spread rate. For details on both parameter estimation and sensitivity analysis, see Appendix S2.

The two other types of analysis comprise two sets of model runs examining the tree spread rate in future environments. In both analyses, we represent a range of possible environmental changes by contrasting a scenario of present-day conditions with two future scenarios that assume a twofold increase in $\beta$ and a $7 \%$ reduction of $\mathrm{t}_{\mathrm{M}}$ - following the FACE study at Duke Forest - but differ in assuming a reduction $(-7 \%)$ or increase $(+6 \%)$ in surface windspeeds. In both analyses, we also explored the sensitivity of spread rate to variation in $\bar{U}_{r}$ and $\Phi$, and to spatially variable vs. spatially homogeneous survival.

In the first set of model runs examining tree spread in future environments, we investigated how predicted spread rates of a typical wind-dispersed tree species differ between these three scenarios, and how sensitive these differences are to variation in $\overline{\mathrm{U}}_{\mathrm{r}}$ and $\Phi$, the two largely unknown parameters. In the present scenario, the typical winddispersed tree was characterized by the following average parameter values: $\beta=25000$ seeds year ${ }^{-1}, t_{M}=25$ years, $t_{L}=200$ years, $\mathrm{t}_{\mathrm{IC}}=3$ years, $\mathrm{v}_{\mathrm{t}},=1.0 \mathrm{~m} \mathrm{~s}^{-1}, \mathrm{~h}_{\mathrm{t}}=25 \mathrm{~m}$ and $\mathrm{p}_{\mathrm{r}}=0.7$ (for references and justification, see Table S2). For each of the three environmental scenarios, we also contrasted the relationship between the predicted spread rate and $\overline{\mathrm{U}}_{\mathrm{r}}$ for spatially variable vs. spatially homogeneous survival. We also assessed the role of individual drivers of spread by simulating all other 24 possible scenarios of a full factorial design, with each of the three factors (maturation, fecundity and mean windspeed) either decreasing, remaining unchanged or increasing (i.e. a total of $3^{3}=27$ scenarios).

In the second set of model runs examining tree spread in future environments, we assessed the individualistic response of 12 winddispersed tree species that represent a wide spectrum of dispersal and demographic parameters (Table 1), encompassing almost the full range of these parameters estimated from a much larger set of North American wind-dispersed tree species (Table S2). For each species, we compared the predicted spread rate among the three scenarios, and also assessed how variation in species traits affects changes in the spread rate between current and future conditions.

Table 1 Parameter estimates (mean values) for 12 wind-dispersed tree species selected to assess inter-specific variation in spread rate.

\begin{tabular}{|c|c|c|c|c|c|c|c|c|}
\hline Tree species & $\begin{array}{l}\text { Species } \\
\text { abbreviation }\end{array}$ & $\begin{array}{l}\text { Fecundity } \\
(\text { seeds tree } \\
\left.\text { year }^{-1}\right)\end{array}$ & $\begin{array}{l}\text { Maturation } \\
\text { age (years) }\end{array}$ & $\begin{array}{l}\text { Longevity } \\
\text { (years) }\end{array}$ & $\begin{array}{l}\text { Interval } \\
\text { between good } \\
\text { seed crops (years) }\end{array}$ & $\begin{array}{l}\text { Seed terminal } \\
\text { velocity } \\
\left(\mathrm{m} \mathrm{s}^{-1}\right)\end{array}$ & $\begin{array}{l}\text { Tree } \\
\text { height } \\
(\mathrm{m})\end{array}$ & $\begin{array}{l}\text { Proportional } \\
\text { height of } \\
\text { seed release }\end{array}$ \\
\hline Acer rubrum & $\mathrm{AR}$ & 21440 & 8 & 80 & 1.0 & 0.67 & 17.2 & 0.66 \\
\hline Acer saccharum & AS & 1750 & 40 & 300 & 5.0 & 0.82 & 31.0 & 0.75 \\
\hline Betula lenta & BL & 449940 & 40 & 150 & 1.5 & 1.60 & 24.0 & 0.75 \\
\hline Betula papyrifera & $\mathrm{BP}$ & 27240 & 30 & 120 & 2.0 & 0.55 & 21.0 & 0.75 \\
\hline Carpinus caroliniana & $\mathrm{CC}$ & 3520 & 15 & 75 & 4.0 & 0.98 & 11.2 & 0.74 \\
\hline Fraxinus americana & FA & 15090 & 37 & 260 & 4.0 & 1.41 & 18.7 & 0.70 \\
\hline Liquidambar styraciftua & LS & 87330 & 25 & 150 & 1.0 & 1.05 & 25.6 & 0.63 \\
\hline Liriodendron tulipifera & $\mathrm{LT}$ & 96850 & 20 & 200 & 1.0 & 1.48 & 26.1 & 0.66 \\
\hline Picea glauca & PG & 7200 & 25 & 200 & 7.5 & 0.62 & 23.0 & 0.75 \\
\hline Pinus strobus & PS & 65000 & 15 & 400 & 6.5 & 0.93 & 46.0 & 0.75 \\
\hline Pinus taeda & PT & 1550 & 7 & 190 & 8.0 & 0.70 & 31.5 & 0.72 \\
\hline Tilia americana & TA & 2330 & 30 & 140 & 1.0 & 2.92 & 16.0 & 0.75 \\
\hline
\end{tabular}

For references, see Table S3. 


\section{RESULTS}

\section{Determinants of wind-driven tree spread}

A stepwise rank-regression analysis revealed that the natural interspecific variation in maturation time has the strongest impact on winddriven spread of trees (Fig. 2). Other important determinants of variation in spread rate are post-dispersal survival, seed terminal velocity, fecundity, mean horizontal windspeed and, to a lesser extent, tree height. Intercrop interval, the standard deviation of vertical wind velocity and longevity had relatively little impact, and the fractional height of seed release was the least influential parameter.

\section{Effects of environmental changes on wind-driven spread}

For a typical North American wind-dispersed tree species, predicted spread rates are low for most scenarios and parameter values, with rates $>50 \mathrm{~m}$ year $^{-1}$ restricted to high-survival $(\Phi)$ and high-threshold windspeed for seed abscission $\left(\bar{U}_{\mathrm{r}}\right)$ (Fig. 3). Spread faster than $100 \mathrm{~m}$ year $^{-1}$ occurs only under high and spatially homogeneous survival (Fig. 3). Spread rate predictions for 12 tree species show that three species (AR, PS and PT; see Table 1 for species abbreviations) can spread faster, up to $c .1100 \mathrm{~m}$ year $^{-1}$, but again only under high $\Phi$ and $\bar{U}_{r}$ (Fig. 4). Overall, spatially uniform survival always yields faster spread than spatially variable survival, especially under high $\bar{U}_{\mathrm{r}}$ for both the hypothetical typical species (Fig. 3) and the 12 real species (compare Fig. 4 and Fig. S8). Model runs assuming spatially stochastic survival reveal relative narrow confidence bounds around the constant survival function and, again, faster rates compared with hump-shaped survival with the same mean (Fig. S5). The projected higher fecundity and earlier maturation are predicted to increase spread even under a $7 \%$ reduction in surface windspeed; in fact, the two future scenarios of either reduced or increased windspeed yielded similar spread rates, especially if seeds abscise only in strong winds (Figs 3 and 4). Species with low lifetime reproduction are expected to exhibit the strongest response to the projected environmental changes (i.e. higher futureto-present spread ratio) (Fig. S7). The full factorial analysis shows that predicted spread rates of the scenarios assuming enhanced fecundity are ranked higher than those assuming earlier maturation or stronger winds in general, and especially if survival is low (Table S5) and if seeds abscise only in strong winds (Table S6).

\section{DISCUSSION}

We expanded the IBE model to introduce a mechanistic modelling framework capable of incorporating projected changes in key biological, environmental and physical conditions expected to affect the spread of wind-dispersed plants. For a 'typical' North American wind-dispersed tree species, this model revealed that the spread rate is unlikely to match shifts in surface temperature projected for most forest biomes for the middle of the current century (Loarie et al. 2009). Only under the particular circumstance of high post-dispersal survival and seed abscission biased to strong winds might a typical wind-dispersed tree spread at rates of 100-200 $\mathrm{m}$ year $^{-1}$ comparable with the temperature shift projected for temperate conifer forests (Loarie et al. 2009). Three of the 12 specific species examined, representing different favourable combinations of dispersal and demographic parameters, are predicted to spread at faster rates projected for other North American forest biomes (Loarie et al. 2009), but only under the same particular circumstances. By the middle of the current century, the spread of North American wind-dispersed trees is thus expected to lag behind shifts in mean surface temperature; exceptions may occur under favourable environmental conditions for a few species exhibiting specific trait combinations.

This key finding should be compared with previous assessments of the potential of trees for fast spread of 300-500 $\mathrm{m}$ year $^{-1}$. Clark et al. (2001) suggested that high $\mathrm{R}_{0}$ and LDD are necessary to produce such fast spread rates. The high $\mathrm{R}_{0}$ values they implemented (5000-50 000) necessitate unrealistically high survival given the empirical range of annual fecundity of trees (Tables 1 and Table S2). High LDD in this approach was produced by a phenomenological dispersal model calibrated from local seed trap data and extrapolated well beyond the calibration range. Employing a WALD kernel-based Fisher equation, Thompson \& Katul (2008) reproduced fast spread of up to $700 \mathrm{~m}_{\text {year }}{ }^{-1}$ for some species, yet their results critically rely on a continuous biomass assumption that disregards the discrete nature of seeds. If a minimum biomass threshold corresponding to a single seed is imposed on such continuous models, the extreme tails of the biomass propagating front become censored, reducing their predicted spread rates by factors of $2-5$, making them compatible with the results reported here. Using a Lagrangian mechanistic wind-dispersal model, Kuparinen et al. (2009) predicted fast spread (650$800 \mathrm{~m} \mathrm{year}^{-1}$ ) in warmer future atmosphere for a hypothetical
Figure 2 Results of a stepwise rank regression for five dispersal (grey boxes) and five demographic (black boxes) parameters determining spread rate of North American wind-dispersed tree species. The parameters are arranged according to the absolute value of the regression standardized coefficients, and the range of values for each parameter is given at the bottom line (for details, see Table S2).

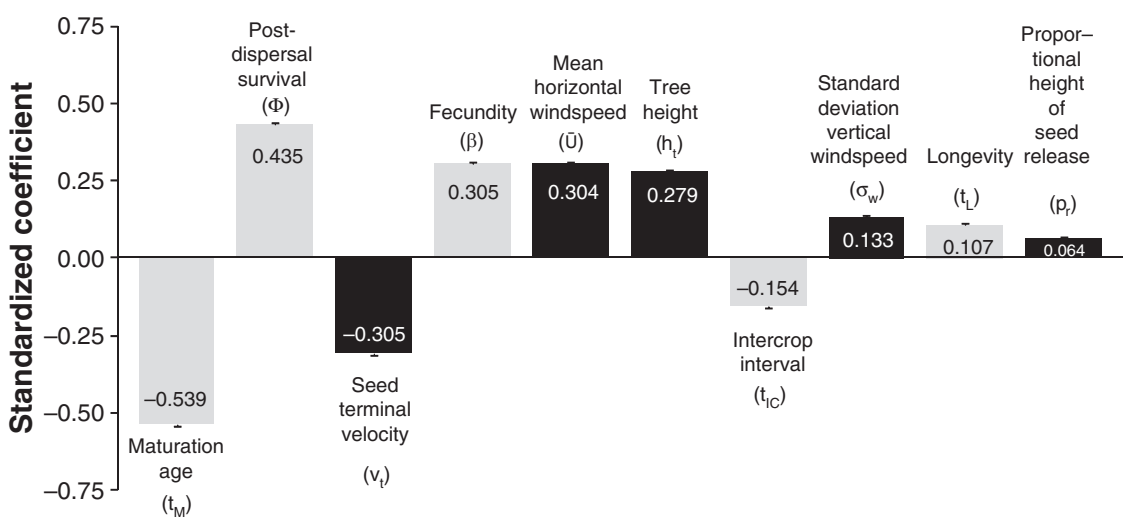

Range in 3-60 sensitivity years analysis $\begin{array}{cc}10^{-5}- & 0.4-3.4 \\ 0.02 & \mathrm{~ms}^{-1}\end{array}$

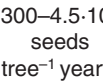
seeds tree ${ }^{-1}$ year

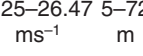

Variable 


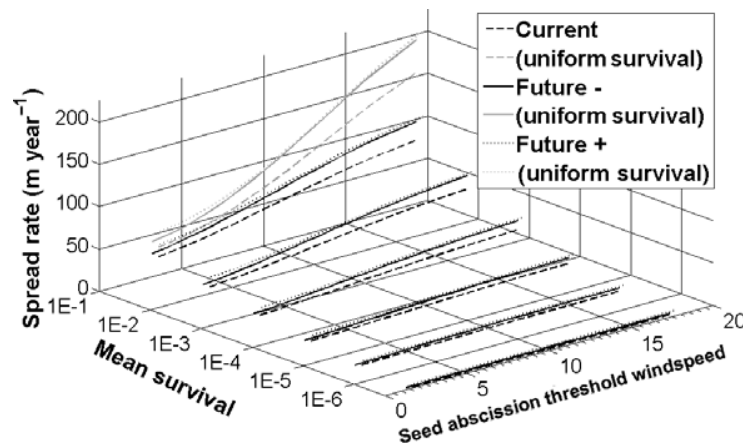

Figure 3 Model results for the spread rate of a hypothetical typical North American wind-dispersed tree species (see text for parameter values). Spread rate varies with (1) mean post-dispersal seed-to-adult survival; (2) minimum windspeed required for seed abscission to occur; and (3) three environmental scenarios, representing the current conditions (dashed), the projected condition of higher fecundity, earlier maturation and $7 \%$ reduction (dotted) or $6 \%$ increase (solid) in mean surface windspeed. Black lines indicate variable (hump-shaped) survival function; grey lines, shown only for the highest (0.024) mean survival, indicate spatially uniform survival function.

(12 $\mathrm{m}$ high) tree only if the seed terminal velocity is exceptionally low $\left(0.2 \mathrm{~m} \mathrm{~s}^{-1}\right)$, a value beyond the observed range of 54 measured North American wind-dispersed tree species (Table S2). For a terminal velocity of $1 \mathrm{~m} \mathrm{~s}^{-1}$, typical for North American wind-dispersed tree species (Table S2 and Fig. S6), Kuparinen et al. (2009) predicted spread rates of only 4-8 $\mathrm{m}_{\text {year }}{ }^{-1}$.

Our mechanistic approach can assess how spread rate depends on variation in species traits vs. environmental conditions. The global sensitivity analysis emphasizes the importance of three traits: maturation time, fecundity and seed terminal velocity (Fig. 2). Our results also highlight the importance of non-random seed abscission (Figs 3 and 4), a parameter likely to be internally controlled by seeddislodging mechanisms (Greene \& Johnson 1992). Comparing the predicted spread rate among 12 tree species demonstrates the importance of specific combinations of life-history traits. For example, the three fastest-spreading species (AR, PS and PT; see Table 1 for species abbreviation) share two or more of the following traits: low terminal velocity (AR and PT), tall tree height (PT and especially PS), relatively high fecundity (PS) and early maturation (AR and PT). However, each of them shares some properties typical of slowspreading species (AS, BL, CC, FA and TA), such as short tree height (AR), low fecundity (PT) and long intercrop interval (PS and PT).

Among the two physical determinants of wind-driven spread, the variation in $\overline{\mathrm{U}}$ was found to be more significant than $\sigma_{\mathrm{w}}$, as expected from WALD's formulation (see Appendix S1). Variation in postdispersal seed-to-adult survival, reflecting both internal (e.g. seed size) and external (e.g. nutrient availability) factors, crucially affected the spread rate. Although Clark et al. (2001, p. 547) have previously noted that low survival prevents fast spread, all other studies of spatial spread have either ignored post-dispersal survival or amalgamated it with fecundity (by considering only $\mathrm{R}_{0}$ ). Furthermore, we found that under hump-shaped spatially variable survival, spread rates are considerably slower than under spatially uniform or spatially stochastic survival with the same mean (Fig. 3 and Fig. S5). Presumably, this is primarily due to the much lower survival far from the source under this hump-shaped function (Fig. S4), suggesting that fast spread necessitates high survival far from the source.

Data on a recent fast spread of a North American wind-dispersed tree species supports this hypothesis. In the glacier forelands at Glacier Bay, Alaska, Sitka spruce (Picea sitchensis) trees were estimated
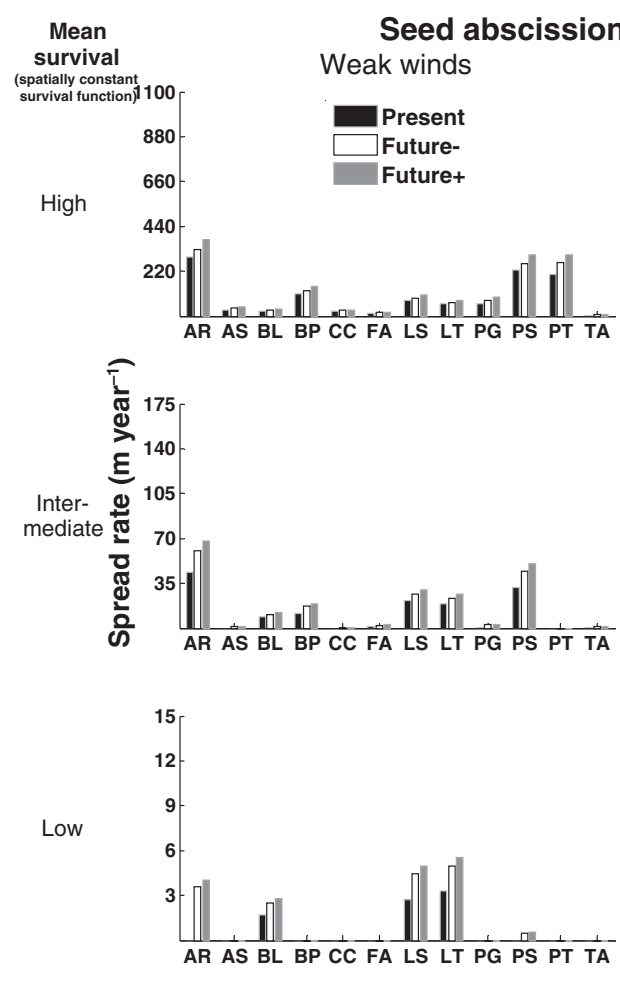
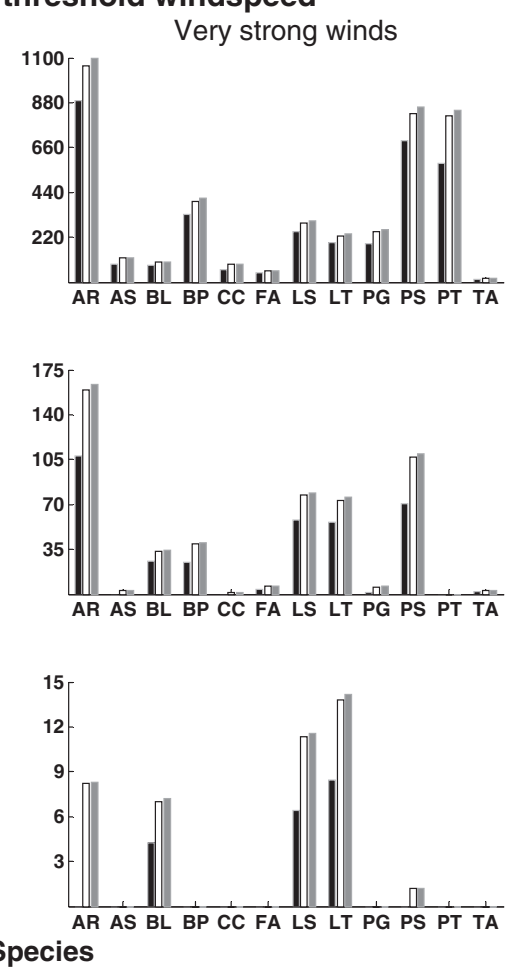

Figure 4 Model results for the spread rate of 12 wind-dispersed tree species (see Table 1 for species abbreviation and parameter values). Results are presented for two extreme levels of seed abscission threshold windspeed (columns), and three levels of mean post-dispersal seed-to-adult survival (rows), across the three environmental scenarios (legend in top left panel). Seed abscission threshold windspeed $\left(\overline{\mathrm{U}}_{\mathrm{r}}\right)$ is $1.75 \mathrm{~m} \mathrm{~s}^{-1}$ (weak winds) and $16.00 \mathrm{~m} \mathrm{~s}^{-1}$ (very strong winds). Mean survival over all space $(\Phi)$ is 0.024 (high), 0.00024 (intermediate) or 0.0000024 (low). Survival function is uniform in space. 
to advance at rates of $300-400 \mathrm{~m} \mathrm{year}^{-1}$ (Fastie 1995). We were unable to gather quantitative information on all 10 parameters required to predict spread rate for this species; yet, it is described as a tall, highly fecund tree with relatively low seed terminal velocity, and intermediate maturation age and intercrop interval (Greene \& Johnson 1995; Peterson et al. 1997; Bonner \& Karrfalt 2008). This set of traits is similar to that of Pinus strobus (PS), one of the three fast-spreading species (Table 1, Fig. 4). To spread on the order of 300$400 \mathrm{~m}$ year $^{-1}$, PS requires high survival coupled with seed abscission only in strong winds (Fig. 4). We have no information on windspeeddependent seed abscission for Sitka spruce (or nearly all other species). Seed sowing experiments and monitoring of established seedlings showed that seed and seedling survival probabilities of Sitka spruce near the glacial retreat front were considerably higher than in more advanced succession stages (Chapin et al. 1994). At the glacial fronts, seed germination was $9-12 \%$ and seedling survival to the second year was 50-85\% (Chapin et al. 1994). Such exceptionally high survival (see Appendix S1) corresponds to the high survival probabilities required for a rapid spread in Clark et al. (2001) and in our study.

Although this critical condition for the rapid spread (high survival far from the source) can be demonstrated for the early-successional Sitka spruce, it is unclear whether late-successional species can spread at similar rates. More generally, because seed-to-adult survival of trees is rarely high anywhere (Appendix S1), our findings suggest that winddriven spread on the order of $300-500 \mathrm{~m} \mathrm{year}^{-1}$ is unlikely even if environmental change increases fecundity, maturation rates and windspeeds. Future trends in the distribution and availability of establishment opportunities for forest trees are difficult to predict. However, it is difficult to foresee a mechanism associated with current global environmental changes that can generate highly favourable establishment sites far from expanding tree populations in a systematic way equivalent to the above-suggested impact of glacial retreat fronts.

Our results identified two fundamental, yet poorly quantified, determinants of wind-driven spread: biased seed abscission and postdispersal seed-to-adult survival far from the source. The study of biased seed abscission has recently been revitalized by growing evidence for its decisive role in LDD (Wright et al. 2008) and population spread (Soons \& Bullock 2008). Moreover, the stark contrasts between uniform and variable survival in our study demonstrate the need to open the 'black box' of large-scale variation in seed-to-adult survivorship. Large-scale transplant experiments (Savolainen et al. 2007) provide a promising first step towards estimating survival at spatial scales relevant to LDD.

We found that future changes in the spread of North American wind-dispersed trees may be determined almost exclusively by earlier maturation and higher fecundity under elevated $\left[\mathrm{CO}_{2}\right]$, while being insensitive to the projected increases or decreases in surface windspeeds. This finding is surprising, but corresponds to the higher sensitivity of spread rate to maturation time and fecundity, compared with mean horizontal windspeed (Fig. 2). Yet, the projected changes in maturation and fecundity in response to elevated $\left[\mathrm{CO}_{2}\right]$ are based on very few empirical studies, and rigorous assessment of these trends requires further investigation. Furthermore, future changes in the frequency and magnitude of extreme winds (Webster et al. 2005) could substantially alter this conclusion given the critical importance of extreme events in LDD (Nathan et al. 2008). Note, however, that winds are expected to become more extreme mostly over the oceans and not so much over land (Webster et al. 2005).
In this study, we incorporated the primary factors required to set lower and especially upper bounds on spread rates of wind-dispersed trees while keeping our model sufficiently simple to enable analytical spread rate calculations (Appendix S1). Hence, we made simplifying assumptions and ignored further factors such as Allee effects that could limit spread especially in dioecious species like AR (Hastings et al. 2005). In addition, young mature trees are expected to be both shorter and produce less seeds than older individuals, whereas our analyses assumed fecundity and tree height to be constant throughout the reproductive period. We note, however, that relaxing these assumptions can only reduce predicted spread rates, further strengthening our main conclusions and implying that our modelling approach provides a realistic upper bound for the spread rate of wind-dispersed trees. Yet, trees might spread faster if dispersed over longer distances by more extreme winds or by other dispersal agents and humans in particular (Nathan et al. 2008). Furthermore, evolving dispersal traits (Phillips et al. 2008) and anisotropic dispersal might increase spread and warrant further investigation.

Although our study focused primarily on the interactive effects of elevated atmospheric $\left[\mathrm{CO}_{2}\right]$ and changes in windspeeds, projected increases in mean air temperature may also affect plant dispersal and demography. Under certain conditions, higher air temperatures can increase LDD by enhancing sensible heat flux and buoyant production of turbulent kinetic energy (see supplementary material in Kuparinen et al. 2009). However, given the much wider range of wind statistics and the non-random seed abscission considered here, these effects are likely to be minor. Increases in air temperature might also impact carbon accumulation, and could thus further advance maturation age. Yet, increasing temperature and changes in precipitation regimes are projected to increase drought frequency, and thereby reduce plant survival, especially at early establishment stages (McDowell et al. 2008). Given the plethora of such confounding effects and the large uncertainty in forecasting future environments, predictions of plant response should be continually reexamined based on advances in modelling and empirical evidence. Our mechanistic modelling approach provides a framework for assessing how such environmental changes could impact the spread of wind-dispersed plants, given their effects on dispersal and demographic parameters can be made explicit.

In summary, despite the potential for faster spread in future environments - as a result of higher fecundity and earlier maturation and irrespective of the projected positive or negative changes in surface windspeed - most North American wind-dispersed tree species are unlikely to spread rapidly. This is chiefly because seeds of most species are not released only in strong winds and because survival far from the seed source is unlikely to be sufficiently high. Thus, concerns about the ability of trees to track shifting climates (Malcolm et al. 2002; Higgins et al. 2003; McKenney et al. 2007; Svenning \& Skov 2007) still hold.

\section{ACKNOWLEDGEMENTS}

We thank S. Higgins, M. Holyoak, U. Motro, H. Muller-Landau and E. Revilla for intriguing discussion of earlier drafts, and J. Fryxell and four anonymous referees for their valuable and constructive comments. Support for this study was available through grants from the Israel Science Foundation (ISF-474/02, ISF-150/07 and ISF-FIRST1316/05), the US National Science Foundation (NSF-IBN-9981620, NSF-DEB-0453665), the Ring Foundation, the Simon and Ethel 
Flegg Fellowship, and the Friedrich Wilhelm Bessel Research Award of the Humboldt Foundation to R. Nathan. Y. He acknowledges supports from Mathematics and Information Technology of Complex System (MITACS) project funded by Simon Fraser University and Ouranos and the Canadian Regional Climate Modelling and Diagnosis (CRCMD) network funded by CFCAS and Ouranos. F. Schurr acknowledges support from the European Union through Marie Curie Transfer of Knowledge Project FEMMES (MTKD-CT-2006-042261). G. Katul acknowledges support from NSF-EAR 0628342, NSF-EAR 0635787, NSF-ATM-0724088 and the Bi-National Agricultural Research Development fund (BARD IS-3861-06).

\section{REFERENCES}

Allen, M.R., Stott, P.A., Mitchell, J.F.B., Schnur, R. \& Delworth, T.L. (2000), Quantifying the uncertainty in forecasts of anthropogenic climate change. Nature, 407, 617-620.

Bonner, F.T. \& Karrfalt, R.P. (eds.) (2008). The Woody Plant Seed Manual. United States Department of Agriculture, Forest Service, Agriculture Handbook 727, April. Available at: http://www.nsl.fs.fed.us/nsl_wpsm.html. Last accessed 18 December 2010.

Buckley, Y.M., Brockerhoff, E., Langer, L., Ledgard, N., North, H. \& Rees, M. (2005). Slowing down a pine invasion despite uncertainty in demography and dispersal. J. Appl. Ecol., 42, 1020-1030.

Chapin, F.S., III, Walker, L.R., Fastie, C.L. \& Sharman, L.C. (1994). Mechanisms of primary succession following deglaciation at Glacier Bay, Alaska. Ecol. Monogr., 64, 149-175.

Clark, J.S., Lewis, M. \& Horvath, L. (2001). Invasion by extremes: population spread with variation in dispersal and reproduction. Am. Nat., 157, 537-554.

Engler, R. \& Guisan, A. (2009). MIGCLIM: predicting plant distribution and dispersal in a changing climate. Divers. Distrib., 15, 590-601.

Fastie, C.L. (1995). Causes and ecosystem consequences of multiple pathways of primary succession at Glacier bay, Alaska. Ecology, 76, 1899-1916.

Foley, J.A., DeFries, R., Asner, G.P., Barford, C., Bonan, G., Carpenter, S.R. et al. (2005). Global consequences of land use. Science, 309, 570-574.

Greene, D.F. \& Johnson, E.A. (1992). Fruit abscission in Acer saccharinum with reference to seed dispersal. Can. J. Bot., 70, 2277-2283.

Greene, D.F. \& Johnson, E.A. (1995). Long-distance wind dispersal of tree seeds. Can. J. Bot., 73, 1036-1045.

Hastings, A., Cuddington, K., Davies, K.F., Dugaw, C.J., Elmendorf, S., Freestone, A. et al. (2005). The spatial spread of invasions: new developments in theory and evidence. Ecol. Lett., 8, 91-101.

He, Y.P., Monahan, A.H., Jones, C.G., Dai, A.G., Biner, S., Caya, D. et al. (2010). Probability distributions of land surface wind speeds over North America. J. Geophys. Res. Atmos., 115, D04103.

Higgins, S.I., Clark, J.S., Nathan, R., Hovestadt, T., Schurr, F., Fragoso, J.M.V. et al. (2003). Forecasting plant migration rates: managing uncertainty for risk assessment. J. Ecol., 91, 341-347.

Jablonski, L.M., Wang, X.Z. \& Curtis, P.S. (2002). Plant reproduction under elevated $\mathrm{CO}_{2}$ conditions: a meta-analysis of reports on 79 crop and wild species. New Phytol., 156, 9-26.

Janzen, D.H. (1970). Herbivores and the number of tree species in tropical forests. Am. Nat., 104, 501-528.

Jeltsch, F., Moloney, K.A., Schurr, F.M., Kochy, M. \& Schwager, M. (2008). The state of plant population modelling in light of environmental change. Perspect. Plant Ecol. Evol. Syst., 9, 171-189.

Jongejans, E., Shea, K., Skarpaas, O., Kelly, D., Sheppard, A.W. \& Woodburn, T.L. (2008). Dispersal and demography contributions to population spread of Carduus nutans in its native and invaded ranges. J. Ecol., 96, 687-697.

Katul, G.G., Porporato, A., Nathan, R., Siqueira, M., Soons, M.B., Poggi, D. et al. (2005). Mechanistic analytical models for long-distance seed dispersal by wind. Am. Nat., 166, 368-381.

Kuparinen, A., Katul, G., Nathan, R. \& Schurr, F.M. (2009). Increases in air temperature can promote wind-driven dispersal and spread of plants. Proc. R. Soc. Lond., B, Biol. Sci., 276, 3081-3087.
LaDeau, S.L. \& Clark, J.S. (2006). Elevated $\mathrm{CO}_{2}$ and tree fecundity: the role of tree size, interannual variability, and population heterogeneity. Glob. Change Biol., 12, 822-833.

Levin, S.A., Muller-Landau, H.C., Nathan, R. \& Chave, J. (2003). The ecology and evolution of seed dispersal: a theoretical perspective. Annu. Rev. Ecol. Evol. Syst., 34, 575-604.

Loarie, S.R., Duffy, P.B., Hamilton, H., Asner, G.P., Field, C.B. \& Ackerly, D.D. (2009). The velocity of climate change. Nature, 462, 1052-1055.

Malcolm, J.R., Markham, A., Neilson, R.P. \& Garaci, M. (2002). Estimated migration rates under scenarios of global climate change. J. Biogeogr., 29, 835-849.

McDowell, N., Pockman, W.T., Allen, C.D., Breshears, D.D., Cobb, N., Kolb, T. et al. (2008). Mechanisms of plant survival and mortality during drought: why do some plants survive while others succumb to drought? New Phytol., 178, 719-739.

McKenney, D.W., Pedlar, J.H., Lawrence, K., Campbell, K. \& Hutchinson, M.F. (2007). Potential impacts of climate change on the distribution of North American trees. Bioscience, 57, 939-948.

Morin, X. \& Thuiller, W. (2009). Comparing niche- and process-based models to reduce prediction uncertainty in species range shifts under climate change. Ecology, 90, 1301-1313.

Murphy, J.M., Sexton, D.M.H., Barnett, D.N., Jones, G.S., Webb, M.J. \& Collins, M. (2004). Quantification of modelling uncertainties in a large ensemble of climate change simulations. Nature, 430, 768-772.

Nakišenoviš, N., Alcamo, J., Davis, G., de Vries, B., Fenhann, J., Gaffin, S. et al. (2000). Special Report on Emissions Scenarios. A Special Report of Working Group III of the Intergovernmental Panel on Climate Change. Cambridge University Press, Cambridge, UK.

Nathan, R. (2006). Long-distance dispersal of plants. Science, 313, 786-788.

Nathan, R. \& Casagrandi, R. (2004). simple mechanistic model of seed dispersal, predation and plant establishment: Janzen-Connell and beyond. J. Ecol., 92, 733746.

Nathan, R., Katul, G.G., Horn, H.S., Thomas, S.M., Oren, R., Avissar, R. et al. (2002). Mechanisms of long-distance dispersal of seeds by wind. Nature, 418, 409-413.

Nathan, R., Schurr, F.M., Spiegel, O., Steinitz, O., Trakhtenbrot, A. \& Tsoar, A. (2008). Mechanisms of long-distance seed dispersal. Trends Ecol. Evol., 23, 638-647.

Nekola, J.C. \& White, P.S. (1999). The distance decay of similarity in biogeography and ecology. J. Biogeogr., 26, 867-878.

Neubert, M.G. \& Caswell, H. (2000). Demography and dispersal: calculation and sensitivity analysis of invasion speed for structured populations. Ecology, 81, 1613-1628.

Peterson, E.B., Peterson, N.M., Weetman, G.F. \& Martin, P.J. (1997). Ecology and Management of Sitka Spruce, Emphasizing Its Natural Range in British Columbia. UBC Press, Vancouver.

Phillips, B.L., Brown, G.P., Travis, J.M.J. \& Shine, R. (2008). Reid's paradox revisited: the evolution of dispersal kernels during range expansion. Am. Nat., 172, S34-S48.

Pryor, S.C., Barthelmie, R.J., Young, D.T., Takle, E.S., Arritt, R.W., Flory, D. et al. (2009). Wind speed trends over the contiguous United States. J. Geophys. Res. Atmos., 114, D14105.

Savolainen, O., Pyhäjärvi, T. \& Knürr, T. (2007). Gene flow and local adaptation in trees. Annu. Rev. Ecol. Evol. Syst., 38, 595-619.

Soons, M.B. \& Bullock, J.M. (2008). Non-random seed abscission, long-distance wind dispersal and plant migration rates. J. Ecol., 96, 581-590.

Stiling, P., Moon, D., Hymus, G. \& Drake, B. (2004). Differential effects of elevated $\mathrm{CO}_{2}$ on acorn density, weight, germination, and predation among three oak species in a scrub-oak forest. Glob. Change Biol., 10, 228-232.

Svenning, J.C. \& Skov, F. (2007). Could the tree diversity pattern in Europe be generated by postglacial dispersal limitation? Ecol. Lett., 10, 453-460.

Thompson, S. \& Katul, G. (2008). Plant propagation fronts and wind dispersal: an analytical model to upscale from seconds to decades using superstatistics. Am. Nat., 171, 468-479.

Thuiller, W., Lavorel, S., Araujo, M.B., Sykes, M.T. \& Prentice, I.C. (2005). Climate change threats to plant diversity in Europe. Proc. Natl Acad. Sci. U.S.A., 102, 8245-8250.

Thuiller, W., Albert, C., Araújo, M.B., Berry, P.M., Cabeza, M., Guisan, A. et al. (2008). Predicting global change impacts on plant species' distributions: future challenges. Perspect. Plant Ecol. Evol. Syst., 9, 137-152. 
Wan, H., Wang, X.L. \& Swail, V.R. (2010). Homogenization and trend analysis of Canadian near-surface wind speeds. J. Clim., 23, 1209-1225.

Webster, P.J., Holland, G.J., Curry, J.A. \& Chang, H.R. (2005). Changes in tropical cyclone number, duration, and intensity in a warming environment. Science, 309, 1844-1846.

Wright, S.J., Trakhtenbrot, A., Bohrer, G., Detto, M., Katul, G.G., Horvitz, N. et al. (2008). Understanding strategies for seed dispersal by wind under contrasting atmospheric conditions. Proc. Natl Acad. Sci. U.S.A., 105, 19084-19089.

\section{SUPPORTING INFORMATION}

Additional Supporting Information may be found in the online version of this article:

Appendix S1 Modelling the spread rate of wind-dispersed plants (Table S1; Figs S1-S5).

Appendix S2 Determinants of spread rate in North American winddispersed tree species (Tables S2, S3 and S4; Figs S6 and S7).
Appendix S3 Complementary analyses of current vs. future spread of North American wind-dispersed tree species (Tables S5 and S6; Fig. S8).

As a service to our authors and readers, this journal provides supporting information supplied by the authors. Such materials are peer-reviewed and may be re-organized for online delivery, but are not copy edited or typeset. Technical support issues arising from supporting information (other than missing files) should be addressed to the authors.

Editor, Wilfried Thuiller

Manuscript received 27 September 2010

First decision made 5 November 2010

Manuscript accepted 27 November 2010 